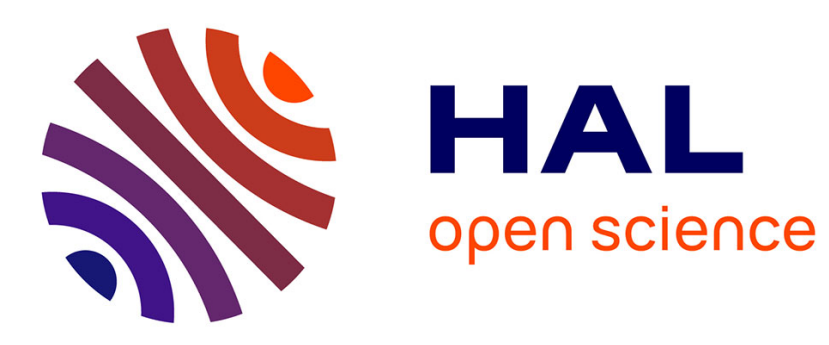

\title{
European Surveillance of antimicrobial resistance in Neisseria gonorrhoeae
}

Michelle Cole, Stephanie Chisholm, Catherine A Ison, Catherine M Lowndes, Steen Hoffmann, Angelika Stary

\section{- To cite this version:}

Michelle Cole, Stephanie Chisholm, Catherine A Ison, Catherine M Lowndes, Steen Hoffmann, et al. European Surveillance of antimicrobial resistance in Neisseria gonorrhoeae. Sexually Transmitted Infections, 2010, 86 (6), pp.427. 10.1136/sti.2010.044164 . hal-00576092

\section{HAL Id: hal-00576092 \\ https://hal.science/hal-00576092}

Submitted on 12 Mar 2011

HAL is a multi-disciplinary open access archive for the deposit and dissemination of scientific research documents, whether they are published or not. The documents may come from teaching and research institutions in France or abroad, or from public or private research centers.
L'archive ouverte pluridisciplinaire HAL, est destinée au dépôt et à la diffusion de documents scientifiques de niveau recherche, publiés ou non, émanant des établissements d'enseignement et de recherche français ou étrangers, des laboratoires publics ou privés. 


\section{European Surveillance of antimicrobial resistance in Neisseria gonorrhoeae}

Michelle J. Cole, Stephanie A. Chisholm, Steen Hoffmann, Angelika Stary, Catherine M. Lowndes, Catherine A. Ison, and the European Surveillance of Sexually Transmitted Infections Network

Michelle Jayne Cole, Stephanie Angela Chisholm, Catherine Lowndes and Catherine Ann Ison, Health Protection Agency, London, UK.

Steen Hoffmann, Statens Serum Institut, Copenhagen, Denmark

Angelika Stary, Ambulatorium für Pilzinfektionen, Vienna, Austria

Correspondence to:

Michelle Cole

Sexually Transmitted Bacteria Reference Laboratory

Health Protection Agency

61 Colindale Avenue

London NW9 5EQ, UK

Tel: 02083276465

Fax: 02083276474

michelle.cole@hpa.org.uk

Key words: Neisseria gonorrhoeae, gonorrhoea, antimicrobial resistance, surveillance 
Members of the European Surveillance of Sexually Transmitted Infections, listed in alphabetical order by countries, are (in addition to the authors):

Austria: Reinhild Strauss, FM for Health, Family and Youth; Belgium: Tania Crucitti, Institute of Tropical Medicine, André Sasse, Scientific Institute of Public Health; Cyprus: Chrystalla Hadjianastassiou, Ministry of Health; Denmark: Susan Cowan, Statens Serum Institut; Estonia: Anneli Uusküla, Tartu University Clinics, Rutta Voiko, West Tallinn Central Hospital; Finland: Eija Hiltunen-Back, National Public Health Institute; France: Véronique Goulet, Institut de Veille Sanitaire, Patrice Sednaoui, Institut Alfred Fournier; Bertille de Barbevrac, National Reference Centre of Chlamydia Infection; Germany: Peter Kohl, Dept. of Dermatology and Venerology, Vívantes Klinikum Neukölln, Osamah Hamouda, Robert-Koch Institute; Greece: Vasileia Konte, Hellenic Centre for Infectious Disease Control, Eva Tzelepi, National Reference Center for N.gonorrhoeae, Hellenic Pasteur Institute; Iceland: Guðrún Sigmundsdóttir, Centre for Infectious Disease Control, Directorate of Health, Guðrun Hauksdottir, Landspitali University Hospital; Ireland: Aidan O'Hora, Health Protection Surveillance Centre, Helen Barry, St. James Hospital; Italy: Paola Stefanelli, Barbara Suligoi, Istituto Superiore di Sanità; Latvia: Judite Pirsko, Elvira Lavrinovica, State Centre of Sexually Transmitted and Skin Diseases; Malta: Christopher Barbara, St Luke's Hospital, Jackie Maistre Melillo, Infectious Disease Prevention and Control Unit, Department of Health Promotion and Disease Prevention; Netherlands: Ineke Linde, GGD Amsterdam, Marianne van der Sande, Rijksinstituut voor Volksgezondheid en Milieu; Norway: Hilde Klovstad, Norwegian Institute of Public Health, Vegard Skogen, UNN Tromsø Universitetssykehuset; Portugal:Jacinta Azevedo, General Directorate of Health (DGS), Maria-José Borrego, Instituto Nacional de Saude Dr Ricardo Jorge; Slovak Republic; Jan Mikas, National Public 
Health Agency of the Slovak Republic; Slovenia: Irena Klavs, Centre for Communicable Diseases, Institute of Public Health of the Republic of Slovenia, Alenka Andlovic, Institute of Microbiology and Immunology, University of Ljubljana; Spain: Julio Vazquez, Mercedes Diez, Instituto de Salud Carlos III; Sweden: Anders Blaxhult, Inga Velicko, Swedish Institute for Infectious Disease Control, Hans Fredlund, Magnus Unemo, Swedish Reference Laboratory for Pathogenic Neisseria, Orebro University Hospital; Turkey: Peyman Altan, General Directorate of Primary Care Services, Ministry of Health; United Kingdom: Lesley Wallace, Health Protection Scotland, Hugh Young, Scottish Bacterial Sexually Transmitted Infections Reference Laboratory, Mike Catchpole, Gwenda Hughes, Emma Savage, Health Protection Agency 


\section{ABSTRACT}

Objective: To perform a European sentinel surveillance study for antimicrobial resistance (AMR) in Neisseria gonorrhoeae as part of the European Surveillance of Sexually Transmitted Infections (ESSTI) Programme.

Methods: From 2006 to 2008 seventeen countries participated in the AMR surveillance programme. The susceptibility of a total of 3528 consecutive isolates was tested using the agar dilution breakpoint technique or Etests for ciprofloxacin, penicillin, tetracycline, azithromycin, spectinomycin and ceftriaxone. Nitrocefin was used to detect $\beta$-lactamase activity.

Results: Rates of resistance to ciprofloxacin, the previously recommended treatment, were high across Europe $(42 \%-52 \%)$ indicating usage is no longer appropriate. While resistance to the currently recommended treatment, ceftriaxone, was not demonstrated, a concerning upward drift in the MIC distribution was identified since an earlier European study in 2004. No resistance to spectinomycin was observed whereas azithromycin resistance varied from $2 \%$ to $7 \%$ and isolates from Scotland $(n=4)$ and Ireland $(n=1)$ showed high level resistance (MIC $>256$ $\mathrm{mg} / \mathrm{l})$. High-level resistance to tetracycline and penicillin remained relatively constant at $16 \%$ and $12 \%$ respectively.

Conclusions: AMR is an ongoing problem in Europe, with high rates of resistance to many previously recommended therapeutic agents observed in many European countries. Continual European and global surveillance of AMR in N. gonorrhoeae is essential to monitor for increasing, emerging and high-level resistance to therapeutically relevant agents and to inform treatment guidelines so optimum treatment therapies are administered. 


\section{INTRODUCTION}

Neisseria gonorrhoeae is the causative agent of gonorrhoea, a sexually transmitted infection (STI) which continues to present a significant public health problem across Europe and Worldwide, with approximately 62 million new cases diagnosed globally each year.[1] Gonorrhoea primarily presents as a mucosal infection of the lower genital tract, which is predominantly symptomatic in men presenting as urethritis but is thought to be asymptomatic in about $50 \%$ of women. N. gonorrhoeae can ascend to the upper genital tract, if undiagnosed or inadequately treated, leading to complications such as infertility which occur more frequently in women or can invade the blood causing disseminated infections (e.g. septic arthritis, meningitis, endocarditis). Gonorrhoea is associated with an increase in the acquisition and transmission of HIV.[2] Treatment of gonorrhoea, therefore, is essential not only for individual patient management but also to intercept transmission chains and so reduce the overall disease burden. However, successful treatment of gonorrhoea is severely compromised by the propensity of $N$. gonorrhoeae to develop resistance to antimicrobials used for therapy, and the subsequent worldwide spread of resistant gonococci is well documented.[3-8] Therefore, surveillance of antimicrobial resistance (AMR) for N. gonorrhoeae is of paramount importance to inform prescribing policy to ensure patients receive appropriate therapy.

The European Surveillance of Sexually Transmitted Infections (ESSTI) project was established in 2002 to develop and coordinate epidemiological and laboratory surveillance of sexually transmitted infections (STIs) in the European region in order to better inform about STI prevention, care and control. Surveillance data collected 
by ESSTI demonstrated that the number of cases of gonorrhoea, from 1998 to 2007, rose in Western Europe, remained steady in Central Europe and declined in the two Eastern European countries that supplied data.[9] However there was wide variation in the rate of gonorrhoea diagnoses in individual countries, for example, $0.3 / 100,000$ in Italy to $30.8 / 100,000$ in the United Kingdom in 2007.[9] Although this may be due to the heterogeneity in the different surveillance and laboratory systems.[9]

Euro-GASP (European Gonococcal Antimicrobial Surveillance Programme), the laboratory component of ESSTI, performed the first European sentinel surveillance study for AMR in N. gonorrhoeae in 2004.[10] This initial study revealed high resistance rates to ciprofloxacin (31\%) which was used by most countries for treatment at that time, and tetracycline $(60 \%)$ and penicillin (21\%), along with azithromycin resistance of over $5 \%$ observed for the first time. Surveillance studies are essential to demonstrate when resistance rates to antimicrobials exceed $5 \%$, the level at which a therapeutic agent should no longer be recommended as first line therapy.[11] In addition, it is of particular importance to monitor emerging resistance to the current recommended therapy across Europe, the third generation cephalosporins.[12]

Euro-GASP has subsequently performed sentinel surveillance studies in 2006 to 2008 to continue to monitor the prevalence of antimicrobial-resistant $N$. gonorrhoeae across Europe. 


\section{METHODS}

\section{Participating laboratories}

Seventeen $N$. gonorrhoeae reference or specialist laboratories participated in the ESSTI N. gonorrhoeae AMR surveillance study as previously described.[9] Three participating laboratories had complete coverage of all diagnosed gonorrhoea in the country (Denmark, Scotland and Sweden). Eight laboratories had good national coverage, defined as representations from all areas of the country but not every case of diagnosed gonorrhoea (Belgium, England and Wales, France, Greece, Latvia, Malta, Portugal and Spain). Six laboratories had good coverage of a particular region of the country but not national coverage (Austria, Germany, Ireland, Italy, The Netherlands and Slovenia).

\section{Collection of $\boldsymbol{N}$. gonorrhoeae isolates}

The aim of the isolate collection was to obtain a minimum of 1000 isolates across Europe, where possible, to maximise the ability to detect changes over time. Each country was asked to contribute 100 isolates from $1^{\text {st }}$ June each year. Some laboratories (Austria, Portugal, Slovenia, Germany, Greece, Malta, Italy and Latvia) collected isolates prior to the start date due to a low collection rate. Laboratories were requested to collect one isolate from each patient.

Pure cultures, 18-24 hours old, were saved on Microbank beads (Pro-lab Diagnostics, Richmond Hill, Canada) and stored at $-70^{\circ} \mathrm{C}$. The isolates were then sent frozen on dry ice to one of three laboratories for susceptibility testing (Health 
Protection Agency (HPA), London, UK; Statens Serum Institut, Copenhagen, Denmark and Outpatients' Centre for Diagnosis of Infectious Venero-Dermatological Diseases, Vienna, Austria).

For each isolate the following data where available was collected: Date specimen obtained, sex and age.

\section{Antimicrobial Susceptibility testing}

Isolates were retrieved on GC agar (Becton, Dickinson and Company, Le Pont de Claix, France) with 1\% Vitox (Oxoid, Basingstoke, UK) and incubated for 18-24 hours at $36^{\circ} \mathrm{C}$ in $5 \% \mathrm{CO}_{2}$. Isolates were confirmed to be N. gonorrhoeae by Gram stain, oxidase test and either the Gonogen II test (Bioconnections, Leeds, UK) or the Microtrak test (Trinity Biotech, Wicklow, Ireland) according to manufacter's instructions. Susceptibility testing was performed at the three centres using the agar dilution breakpoint technique for ciprofloxacin, azithromycin, penicillin and tetracycline. In addition, spectinomycin was tested for the 2008 isolates.

The isolates were sub-cultured once before susceptibility testing was performed. Suspensions of cultures aged $18-24$ hours were prepared equivalent to McFarland's standard 0.5 (approximately $10^{4} \mathrm{cfu} / \mu \mathrm{l}$ ) in saline. Using the Multipointelite multipoint inoculator (Mast Group Ltd, Bootle, UK), suspensions were inoculated onto GC agar plates with $1 \%$ Vitox, containing a panel of antimicrobials at the following breakpoint concentrations; penicillin (1 mg/L), ciprofloxacin $(0.5 \mathrm{mg} / \mathrm{L})$, tetracycline (1 and $8 \mathrm{mg} / \mathrm{L})$, azithromycin $(0.5 \mathrm{mg} / \mathrm{L})$ and spectinomycin $(64 \mathrm{mg} / \mathrm{L})$. 
Plates were incubated for $18-24$ hours at $36^{\circ} \mathrm{C}$ in $5 \% \mathrm{CO}_{2}$ and the presence of bacterial growth was recorded for each isolate. All isolates were tested for penicillinase production using the chromogenic reagent, Nitrocefin (Oxoid), following manufacturer's instructions. The ceftriaxone MIC of isolates was determined using Etests (AB bioMérieux, Solna, Sweden) according to the manufacturer's instructions. Azithromycin MICs were determined by Etest for isolates displaying resistance by the agar dilution breakpoint technique.

The Clinical and Laboratory Standards Institute (CLSI) breakpoints for susceptibility or resistance[13], as widely used in European countries, were used for ciprofloxacin, penicillin, tetracycline and spectinomycin. The European Committee on Antimicrobial Susceptibility Testing (EUCAST) breakpoints[14] were followed for azithromycin and ceftriaxone, as CLSI have not yet recommended a breakpoint for azithromycin and the lower EUCAST breakpoints for ceftriaxone ensure levels of decreased susceptibility are not under estimated. In summary, strains were categorised according to the following definitions: Ciprofloxacin resistant (MICs $\geq 1$ $\mathrm{mg} / \mathrm{L})$; penicillinase producing $N$. gonorrhoeae (PPNG) ( $\beta$-lactamase positive); tetracycline resistant $N$. gonorrhoeae (TRNG) (MICs $\geq 16 \mathrm{mg} / \mathrm{L}$ ); chromosomally resistant $N$. gonorrhoeae (CMRNG) (penicillin MICs $\geq 2 \mathrm{mg} / \mathrm{L}$ and $\beta$-lactamase negative and tetracycline MICs $2-8 \mathrm{mg} / \mathrm{L}$ ); azithromycin resistant (MICs $\geq 1 \mathrm{mg} / \mathrm{L}$ ); spectinomycin resistant (MICs $\geq 128 \mathrm{mg} / \mathrm{L}$ ) and ceftriaxone decreased-susceptibility (MICs > $0.125 \mathrm{mg} / \mathrm{L})$. 


\section{Statistical analysis}

Fisher's exact test was used to assess the significance of difference between the resistance rates from 2006 to 2008. The significance of difference between all countries and countries that participated in all of the three years was assessed using Fisher's exact test. The differences between the resistance rates of each antimicrobial between all participating countries in each year was assessed using the chi-squared test for penicillin, tetracycline and ciprofloxacin, and the Fisher's exact test was used for azithromycin and fully susceptible strains. P values less than 0.05 were categorised as significant.

\section{Quality assurance and control}

Laboratory personnel from each of the three testing centres were trained in a single centre (the HPA) to ensure consistency of technique. Quality control strains (WHO A (spectinomycin resistant), WHO G (penicillin and tetracycline resistant), WHO J (PPNG, ciprofloxacin and tetracycline resistant), and G06-1153 (azithromycin resistant clinical strain)) were included in each susceptibility testing run. To ensure consistent quality assurance (QA), two different panels of 10 strains were tested by the three centres each year using all methods and the results from all three centres were compared. 


\section{RESULTS}

\section{Isolate and patient data}

A total of 3645 isolates were collected over the three year period (Table 1) and after the removal of duplicate specimens 3528 isolates were retrieved and confirmed to be N. gonorrhoeae. The overall retrieval rate was $97 \%$ (3528/3645). The number of isolates tested from each country varied from 12 (Germany 2008) to 114 (Spain 2006) (Table 2). Of the 3528 isolates tested, further data was available for 3494 isolates. The majority of gonococci $(80 \% ; 2798 / 3494)$ were collected from men whereas 19\% (675/3494) were from women. Gender was unknown for the remaining 21 isolates (Table 1). The age range of the patients was 6 to 81 years, with a mode and median age of 24 and 31 years respectively.

\section{Antimicrobial susceptibility}

Data from all countries for each year was combined to determine the overall resistance rates (Figure 1). The list of participating countries varied slightly for each year (Table 2). However, there were small, non-significant differences (Fisher's exact test $p>0.05$ ) when the resistance rates from the countries that participated in all of the three years was compared to all countries in each of the three years (Tables 2 and 3). For each antimicrobial in each year there was considerable variation in the resistance rates between the countries (chi-squared and Fisher's exact test $p \leq 0.01$ ) (Tables 2 and 3). 
The overall level of ciprofloxacin resistance significantly increased from 42\% in 2006 to $51 \%$ (Fishers exact test $p<0.001$ ). All countries displayed more than $5 \%$ resistance to ciprofloxacin in each year tested (Table 2). No apparent trend for azithromycin resistance rates was evident (Table 2). The modal MIC of azithromycin resistant isolates in all three years was $1.0 \mathrm{mg} / \mathrm{L}$. Four isolates in 2007 from Scotland and one from Ireland in 2008 were highly resistant to azithromycin (>256mg/L). High level resistance to penicillin (PPNG) and tetracycline (TRNG) remained fairly constant over the study period (Table 3 - Please put as web only) and there was no apparent trend from 2006 to 2008 for chromosomally mediated resistance to both penicillin and tetracycline (CMRNG).

No isolates demonstrated decreased-susceptibility to ceftriaxone. The modal MIC of isolates to ceftriaxone was $0.008 \mathrm{mg} / \mathrm{L}$ in 2006 and 2007 and $0.004 \mathrm{mg} / \mathrm{L}$ in 2008 (Figure 2).

\section{Quality assurance}

The overall concordance for the agar dilution breakpoint technique was $94 \%$ (94/100). For the agar dilution technique there were six occasions when the same category of resistance was not achieved for penicillin $(n=4)$, ciprofloxacin $(n=1)$ and azithromycin $(n=1)$ for each QA isolate. However all of these six strains had a MIC on a breakpoint. There was $100 \%$ concordance for 10 strains tested by azithromycin Etest. Eighty-five percent (17/20) concordance was achieved for the 20 strains tested by ceftriaxone Etest, where the MICs differed by less than two doubling dilutions. The internal quality control strains results were within one dilution of the expected ranges. 
Table 1. Isolate and patient characteristics

\begin{tabular}{lcccc}
\cline { 2 - 5 } & $\mathbf{5}$ & \multicolumn{3}{c}{ Year } \\
\cline { 2 - 5 } & $\mathbf{2 0 0 6}$ & $\mathbf{2 0 0 7}$ & $\mathbf{2 0 0 8}$ & All years \\
\hline No. of isolates collected & 840 & 1471 & 1334 & 3645 \\
No. of isolates with available & & & & \\
data & 836 & 1374 & 1284 & 3494 \\
No. of males (\%) & $688(82)$ & $1111(81)$ & $999(78)$ & $2798(80)$ \\
No. of females (\%) & $145(17)$ & $253(18)$ & $277(22)$ & $675(19)$ \\
No. where sex is unknown (\%) & $3(0.4)$ & $10(0.7)$ & $8(0.6)$ & $21(0.6)$ \\
Maximum age (years) & 71 & 81 & 75 & 81 \\
Minimum age (years) & 14 & 15 & 6 & 6 \\
Median age (years) & 31.1 & 31.7 & 30.5 & 31.1 \\
Modal age (years) & 25 & 24 & 23 & 24 \\
\hline
\end{tabular}


Table 2. Resistance rates by ciprofloxacin and azithromycin antimicrobials and percentage of strains that were fully susceptible in each participating country

\begin{tabular}{|c|c|c|c|c|c|c|c|c|c|c|c|c|}
\hline \multirow[b]{3}{*}{ Country } & \multirow{2}{*}{\multicolumn{3}{|c|}{$\begin{array}{l}\text { No. of isolates } \\
\text { tested }\end{array}$}} & \multicolumn{6}{|c|}{$\%$ Resistance rates } & \multirow{2}{*}{\multicolumn{3}{|c|}{$\begin{array}{c}\% \text { Fully } \\
\text { susceptible } \\
\text { strains }\end{array}$}} \\
\hline & & & & \multicolumn{3}{|c|}{ Ciprofloxacin } & \multicolumn{3}{|c|}{ Azithromycin } & & & \\
\hline & 2006 & 2007 & 2008 & 2006 & 2007 & 2008 & 2006 & 2007 & 2008 & 2006 & 2007 & 2008 \\
\hline Austria & 19 & 107 & 110 & 36.8 & 64.5 & 80.9 & 0 & 1.9 & 0.9 & 26.3 & 11.2 & 9.1 \\
\hline Belgium & 109 & 107 & 108 & 58.7 & 62.6 & 56.5 & 1.8 & 12.1 & 0 & 9.2 & 14.0 & 10.2 \\
\hline Denmark & 111 & 110 & 110 & 45.9 & 67.3 & 70.0 & 8.1 & 13.6 & 6.4 & 1.8 & 7.3 & 0 \\
\hline England \& Wales & 110 & 112 & 112 & 15.5 & 25.9 & 30.4 & 0 & 4.5 & 0 & 14.5 & 16.1 & 5.4 \\
\hline France & ND & 110 & 107 & ND & 44.5 & 43.9 & ND & 4.5 & 0 & ND & 7.3 & 13.1 \\
\hline Germany & ND & 84 & 12 & ND & 59.5 & 58.3 & ND & 2.4 & 8.3 & ND & 7.1 & 8.3 \\
\hline Greece & ND & 86 & 110 & ND & 55.8 & 63.6 & ND & 27.9 & 3.6 & ND & 0 & 0.9 \\
\hline Ireland & ND & ND & 92 & ND & ND & 29.3 & ND & ND & 2.2 & ND & ND & 4.3 \\
\hline Italy & ND & 92 & ND & ND & 59.8 & ND & ND & 1.1 & ND & ND & 5.4 & ND \\
\hline Latvia & ND & 33 & ND & ND & 21.2 & ND & ND & 3.0 & ND & ND & 57.6 & ND \\
\hline Malta & ND & 29 & 24 & ND & 89.7 & 83.3 & ND & 0 & 0 & ND & 0 & 0 \\
\hline Netherlands & 108 & 107 & 106 & 38.0 & 36.4 & 50.0 & 1.9 & 2.8 & 0 & 2.8 & 4.7 & 8.5 \\
\hline Portugal & 29 & 72 & 54 & 48.3 & 47.2 & 29.6 & 6.9 & 8.3 & 0 & 0 & 0 & 3.7 \\
\hline Scotland & 110 & 110 & 110 & 28.2 & 31.8 & 31.8 & 2.7 & 9.1 & 0.9 & 10.9 & 13.6 & 0.9 \\
\hline Slovenia & 26 & 28 & 27 & 23.1 & 32.1 & 29.6 & 11.5 & 0 & 3.7 & 0 & 10.7 & 3.7 \\
\hline Spain & 114 & 110 & 103 & 50.9 & 60.9 & 51.5 & 3.5 & 1.8 & 1.0 & 5.3 & 6.4 & 8.7 \\
\hline Sweden & 100 & 110 & 100 & 62.0 & 66.4 & 61.0 & 2.0 & 9.1 & 6.0 & 5.0 & 1.8 & 0 \\
\hline All countries & 836 & 1407 & 1285 & 42 & 52 & 51.2 & 3.2 & 7 & 1.9 & 7.1 & 8.7 & 5.4 \\
\hline $\begin{array}{l}\text { Consistent } \\
\text { participants }\end{array}$ & 836 & 973 & 940 & 42 & 51 & 51.8 & 3.2 & 6.8 & 1.8 & 7.1 & 8.7 & 5.2 \\
\hline
\end{tabular}


(Table 3 to be published as web-only please)

Table 3. Resistance rates for penicillin and tetracycline antimicrobials in each participating country

\begin{tabular}{|c|c|c|c|c|c|c|c|c|c|c|c|c|}
\hline \multirow[b]{3}{*}{ Country } & \multirow{2}{*}{\multicolumn{3}{|c|}{$\begin{array}{l}\text { No. of isolates } \\
\text { tested }\end{array}$}} & \multicolumn{9}{|c|}{$\%$ Resistance rates } \\
\hline & & & & \multicolumn{3}{|c|}{ PPNG } & \multicolumn{3}{|c|}{ TRNG } & \multicolumn{3}{|c|}{ CMRNG } \\
\hline & 2006 & 2007 & 2008 & 2006 & 2007 & 2008 & 2006 & 2007 & 2008 & 2006 & 2007 & 2008 \\
\hline Austria & 19 & 107 & 110 & 5.3 & 15.0 & 10.9 & 26.3 & 16.8 & 5.5 & 0 & 36.4 & 33.6 \\
\hline Belgium & 109 & 107 & 108 & 11.0 & 9.3 & 16.7 & 14.7 & 20.6 & 22.2 & 39.4 & 38.3 & 25.0 \\
\hline Denmark & 111 & 110 & 110 & 20.7 & 19.1 & 11.8 & 24.3 & 24.5 & 14.5 & 20.7 & 42.7 & 39.1 \\
\hline England \& Wales & 110 & 112 & 112 & 3.6 & 8.0 & 10.7 & 6.4 & 8.9 & 7.7 & 12.7 & 18.8 & 9.8 \\
\hline France & ND & 110 & 107 & ND & 10.9 & 13.1 & ND & 18.2 & 19.6 & ND & 25.5 & 25.2 \\
\hline Germany & ND & 84 & 12 & ND & 8.3 & 25.0 & ND & 15.5 & 16.7 & ND & 23.8 & 33.3 \\
\hline Greece & ND & 86 & 110 & ND & 4.7 & 3.6 & ND & 11.6 & 8.2 & ND & 46.5 & 46.4 \\
\hline Ireland & ND & ND & 92 & ND & ND & 8.7 & ND & ND & 14.1 & ND & ND & 17.4 \\
\hline Italy & ND & 92 & ND & ND & 9.8 & ND & ND & 10.9 & ND & ND & 27.2 & ND \\
\hline Latvia & ND & 33 & ND & ND & 9.1 & ND & ND & 12.1 & ND & ND & 12.1 & ND \\
\hline Malta & ND & 29 & 24 & ND & 0 & 4.2 & ND & 10.3 & 4.2 & ND & 75.9 & 70.8 \\
\hline Netherlands & 108 & 107 & 106 & 7.4 & 8.4 & 9.4 & 10.2 & 9.3 & 14.2 & 33.3 & 21.5 & 29.2 \\
\hline Portugal & 29 & 72 & 54 & 6.9 & 8.3 & 9.3 & 3.4 & 15.3 & 24.1 & 41.4 & 48.6 & 14.8 \\
\hline Scotland & 110 & 110 & 110 & 9.1 & 8.2 & 8.2 & 10.0 & 7.3 & 12.7 & 16.4 & 14.5 & 17.3 \\
\hline Slovenia & 26 & 28 & 27 & 11.5 & 7.1 & 7.4 & 3.8 & 0 & 7.4 & 7.7 & 25.0 & 22.2 \\
\hline Spain & 114 & 110 & 103 & 11.4 & 19.1 & 15.5 & 14.0 & 20.0 & 24.3 & 36.0 & 31.8 & 23.3 \\
\hline Sweden & 100 & 110 & 100 & 35.0 & 30.0 & 23.0 & 32.0 & 40.0 & 36.0 & 15.0 & 30.9 & 28.0 \\
\hline All countries & 836 & 1407 & 1285 & 13.3 & 12.2 & 11.7 & 15.2 & 16.5 & 16 & 24.4 & 31.1 & 27.2 \\
\hline $\begin{array}{l}\text { Consistent } \\
\text { participants }\end{array}$ & 836 & 973 & 940 & 13.3 & 14 & 12.8 & 15.2 & 17.7 & 16.9 & 24.4 & 30.6 & 24.9 \\
\hline \multicolumn{13}{|c|}{$\begin{array}{l}\text { *Countries that participated in all three years; Austria, Belgium, Denmark, England and Wales, } \\
\text { The Netherlands, Portugal, Scotland, Slovenia, Spain and Sweden. } \\
\text { ND - No data available } \\
\text { Bold text = highest or lowest \% in that year }\end{array}$} \\
\hline
\end{tabular}




\section{DISCUSSION}

This study provides the first longitudinal data on antimicrobial resistance in gonococci across Europe to inform European treatment guidelines, building on the original surveillance study conducted in 2004.[10] High levels of resistance to ciprofloxacin, a treatment of choice until recent years and a drift in modal MIC to ceftriaxone, the current recommended treatment in most countries, has been detected by this surveillance programme.

Ciprofloxacin resistance has increased dramatically since the first European $N$. gonorrhoeae AMR sentinel study was performed in 2004[10] (31\% to 51\% in 2008) in spite of the fact that ciprofloxacin is no longer recommended for therapy in Europe.[12] The rates are above the recommended $5 \%$ cut-off[11] in all participating countries. Similarly high rates have been demonstrated in individual European countries conducting national surveillance of antimicrobial resistance.[6;15-21] It is evident that ciprofloxacin resistance in N. gonorrhoeae confers no selective disadvantage to the organism as resistance has persisted in countries where relatively little ciprofloxacin is now prescribed for treatment of gonorrhoea.[6] This high level of ciprofloxacin resistance clearly indicates that this antimicrobial is not an appropriate choice for use in any of the countries which participated in this study, unless isolates are known to be susceptible or local resistance rates are known to be less than $5 \%$.

It was encouraging to note that not only were there no examples of decreasedsusceptibility to ceftriaxone over the sampling period, but there was also little change 
in the ceftriaxone modal MICs from 2006 to 2008. However the observation that the modal MICs of $\leq 0.002 \mathrm{mg} / \mathrm{L}$ documented in 2004[10] had increased to $0.008 \mathrm{mg} / \mathrm{L}$ in 2006 and 2007 , and $0.004 \mathrm{mg} / \mathrm{L}$ in 2008 may indicate drift in the susceptibility of the gonococcal population in Europe. It should be noted that ceftriaxone MICs were determined by agar dilution in the 2004 study[10] and by Etest in the current study. While these two methods have been shown to be comparable in our laboratory (data not shown), the possibility that differences in modal MIC are partially due to differences in methodologies cannot be fully excluded. However a similar drift in the population susceptibility to ceftriaxone has been documented recently in England and Wales,[6] and the current study may indicate an emerging problem across Europe, which raises the possibility that MICs may reach a level which leads to treatment failure. The data from this study shows that ceftriaxone is still an appropriate treatment for gonorrhoea in Europe, and as yet treatment failure of urogenital gonorrhoea has not been documented although treatment failure for pharyngeal infection has been recorded.[22] Ceftriaxone is administered parenterally and this has the advantage of ensuring patient compliance and preventing misuse of the agent, which may delay emerging resistance. In contrast, third generations cephalosporins administered orally, such as cefixime, have already resulted in suspected treatment failures[23;24] The current study did not examine resistance to cefixime, but a review of the susceptibility testing panel for European surveillance of gonococcal antimicrobial resistance in 2009 has lead to the amendment of the testing strategy to include cefixime to ensure all therapeutically relevant agents are monitored in future years. 
The threat of emerging resistance to third generation cephalosporins highlights the need to consider future therapeutic options. Azithromycin is not currently a recommended treatment for gonorrhoea[12] but it is proposed that it could be effective as part of a dual therapy in the treatment of pharyngeal gonorrhoea.[25;26] It is therefore important to monitor azithromycin resistance, particularly as the gonococcal population is frequently exposed to this drug as the recommended therapy for treating Chlamydia trachomatis co-infection. The azithromycin resistance rates fluctuated over the study period which is consistent with surveillance studies from the United Kingdom.[6;19] The modal MIC of resistant isolates to azithromycin was $1 \mathrm{mg} / \mathrm{L}$, which is a proposed breakpoint for categorising resistance.[14] Isolates with an MIC on the breakpoint are just one doubling dilution from giving a susceptible category, which is still technically valid, but may explain the inconsistent resistance rates from 2006 to 2008 . The numbers however are small and more longitudinal data is required to establish a trend. Of great concern were the five isolates from Scotland and Ireland exhibiting high-level resistance to azithromycin (>256 mg/L). This resistance phenotype in N. gonorrhoeae was first detected in Scotland in 2004,[27] and has since been reported from England and Wales,[28] Italy[29] and Argentina.[30] Widespread dissemination of high-level azithromycin resistant strains would eliminate azithromycin as a future treatment option. While no resistance to spectinomycin, another therapeutic option, was observed in the current study, problems with availability of this drug in many European countries limits the utility of this as a therapeutic option.

Development and continuation of a European scheme for surveillance of gonococcal antimicrobial susceptibility is a significant achievement which has clear public health 
benefits. This is now an ongoing programme and the focus for the future will be to include more European countries and to overcome some of the acknowledged limitations of the current study such as the variability in numbers submitted from each country annually and differences in the representativeness of the selected isolates for each country. In the current study, there was no difference when the rates of resistance from the countries that participated in all of the three years were compared to all countries in each of the three years. However the overall trends may be biased by the variable number of isolates a country submits in each of the three years and the level of representativeness from each country. Further development of this programme will also focus on increasing sampling numbers from countries with high rates of gonorrhoea and on increasing the frequency of testing so changes in gonococci antimicrobial susceptibilities can be detected more rapidly. In addition, future European surveillance work will focus on ensuring the panel of antimicrobials are therapeutically relevant and have the potential for use in the future. Continued efforts to reliably link epidemiological data to the antimicrobial susceptibility data will be critical in establishing which core groups carry the burden of resistance to help focus intervention strategies.

This study has identified continued high rates of ciprofloxacin resistance, high-level azithromycin resistance and an upward ceftriaxone MIC drift in the European gonococcal population. This demonstrates that $N$. gonorrhoeae AMR surveillance studies are essential to inform treatment guidelines thereby preventing onward transmission and reducing patient morbidity. These studies should continue to monitor for increasing, emerging and high-level resistance, and also to help assist in the decision making process about future antimicrobials options. 


\section{ACKNOWLEDGMENTS}

We thank all the ESSTI collaborators for their contribution to the ESSTI project (www.essti.org). A special thanks to John Anderson, Lene Berthelsen and Maria Haller for performing the laboratory work and Tom Nichols for his statistical advice.

Competing interests: None

\section{CONTRIBUTORS}

MC contributed to the design of the study, performed some of the laboratory work, analysed the data and prepared the manuscript.

SC contributed to the data analysis, the creation of the manuscript and helped supervise the project.

$\mathrm{SH}$ and AS contributed to the design of the study, contributed to the testing of isolates and gave project support throughout the study.

$\mathrm{CL}$ was the surveillance lead for ESSTI and was involved in the creation of the ESSTI network and contributed to the design of the study.

$\mathrm{Cl}$ was the project and microbiology lead for ESSTI and was involved in the creation of the ESSTI network, contributed to the design of the study and supervised the project.

All authors were part of the ESSTI network, participated in project meetings and reviewed the final draft of the manuscript. 


\section{FUNDING}

Financial support for this study was provided by the European Commission (DG

SANCO), Agreement No. 2004210: ESSTI European Surveillance of Sexually

Transmitted Infections.

\section{FIGURE LEGENDS}

Figure 1. Overall incidence of resistant and fully susceptible N. gonorrhoeae (arrows indicate the lowest and highest percentage from participating countries (see Tables 2 and 3)

Figure 2. Ceftriaxone MIC distribution 


\section{REFERENCES}

1 World Health Organisation. Sexually Transmitted Diseases: Gonorrhoea. http://www.who.int/vaccine research/diseases/soa std/en/index2.html (accessed 9 July 2010).

2 Fleming DT, Wasserheit JN. From epidemiological synergy to public health policy and practice: the contribution of other sexually transmitted diseases to sexual transmission of HIV infection. Sex Transm Infect. 1999;75:3-17.

3 WHO Western Pacific Gonococccal Antimicrobial Surveillance Programme. Surveillance of antibiotic resistance in Neisseria gonorrhoeae in the WHO Western Pacific Region, 2006. Commun Dis Intell. 2008;32:48-51.

4 Centers for Disease Control and Prevention. Sexually Transmitted Disease Surveillance 2007 Supplement, Gonococcal Isolate Surveillance Project (GISP) Annual Report 2007. 2009.

http://www.cdc.gov/std/GISP2007/ (accessed 9 July 2010).

5 Dillon JA, Ruben M, Li H et al. Challenges in the control of gonorrhea in South America and the Caribbean: monitoring the development of resistance to antibiotics. Sex Transm Dis. 2006;33:87-95. 
6 Health Protection Agency. GRASP 2008 Report:Trends in Antimicrobial Resistant Gonorrhoea. 2009.

http://www.hpa.org.uk/web/HPAwebFile/HPAweb C/1245914960426 (accessed 9 July 2010).

7 Kubanova A, Frigo N, Kubanov A et al. National surveillance of antimicrobial susceptibility in Neisseria gonorrhoeae in 2005-2006 and recommendations of first-line antimicrobial drugs for gonorrhoea treatment in Russia. Sex Transm Infect. 2008;84:285-289.

8 Tapsall J. Annual report of the Australian Gonococcal Surveillance Programme, 2008. Commun Dis Intell. 2009;33:268-274.

9 European Surveillance of Sexually Transmitted Infections (ESSTI). Sexually Transmitted Infections in Europe. Annual Report 3. Health Protection Agency. 2008. http://www.essti.org/docs/ESSTI Surveillance Annual Report 2008.pdf (accessed 9 July 2010).

10 Martin IM, Hoffmann S, Ison CA. European Surveillance of Sexually Transmitted Infections (ESSTI): the first combined antimicrobial susceptibility data for Neisseria gonorrhoeae in Western Europe. $J$ Antimicrob Chemother. 2006;58:587-593. 
11 Tapsall J. Antimicrobial resistance in Neisseria gonorrhoeae. World Health Organisation. 2001. WHO document WHO/CDS/CSR/DRS/2001.3.

http://whqlibdoc.who.int/hq/2001/WHO CDS CSR DRS 2001.3.pdf (accessed 9 July 2010).

12 Bignell C. 2009 European (IUSTI/WHO) guideline on the diagnosis and treatment of gonorrhoea in adults. Int J STD AIDS. 2009;20:453-457.

13 Clinical and Laboratory Standards Institute (CLSI). Performance standards for antimicrobial susceptibility testing. Seventeenth Informational Supplement. CLSI document M100-S17. Wayne, USA: Clinical and Laboratory Standards Institute 2007.

14 European Committee on Antimicrobial Susceptibility Testing - EUCAST. Breakpoint tables for interpretation of MICs and zone diameters. Version 1.1, p40. 2010.

http://www.eucast.org/fileadmin/src/media/PDFs/EUCAST files/Disk test documents/EUCAST breakpoints v1.1.pdf (accessed 9 July 2010).

15 Enders M, Turnwald-Maschler A, Regnath T. Antimicrobial resistance of Neisseria gonorrhoeae isolates from the Stuttgart and Heidelberg areas of southern Germany. Eur J Clin Microbiol Infect Dis. 2006;25:318-322.

16 Martin G, Cowan S, Hoffmann S. Gonorrhoea 2009. Statens Serum Institut, editor. EPI-NEWS. 2009, 22. 
http://www.ssi.dk/graphics/en/news/epinews/2009/pdf/epinews 22.pdf (accessed 9 July 2010).

17 Farhi D, Hotz C, Poupet $\mathrm{H}$ et al. Neisseria gonorrhoeae antibiotic resistance in Paris, 2005 to 2007: implications for treatment guidelines. Acta Derm Venereol. 2009;89:484-487.

18 Koedijk F, van Veen MG, de Neeling AJ et al. Increasing trend in gonococcal resistance to ciprofloxacin in the Netherlands, 2006-2008. Sex Transm Infect. 2009.

19 Palmer HM, Dave J. Gonococcal antibiotic surveillance in Scotland (GASS):prevalence, patterns and trends in 2008. HPS Weekly Report 43[2009/20]. 2009.

http://www.documents.hps.scot.nhs.uk/ewr/pdf2009/0920.pdf (accessed 9 July 2010).

20 Tzelepi E, Avgerinou H, Flemetakis A et al. Changing figures of antimicrobial susceptibility and serovar distribution in Neisseria gonorrhoeae isolated in Greece. Sex Transm Dis. 2010;37:115-120.

21 Velicko I, Unemo M. Increase in reported gonorrhoea cases in Sweden, 2001 - 2008. Euro Surveill. 2009;14. 
22 Tapsall J, Read P, Carmody C et al. Two cases of failed ceftriaxone treatment in pharyngeal gonorrhoea verified by molecular microbiological methods. J Med Microbiol. 2009;58:683-687.

23 Wang SA, Lee MV, O'Connor $\mathrm{N}$ et al. Multidrug-resistant Neisseria gonorrhoeae with decreased susceptibility to cefixime-Hawaii, 2001. Clin Infect Dis. 2003;37:849-852.

24 Yokoi S, Deguchi T, Ozawa T et al. Threat to cefixime treatment for gonorrhea. Emerg Infect Dis. 2007;13:1275-1277.

25 Furuya $\mathrm{R}$, Nakayama $\mathrm{H}$, Kanayama $\mathrm{A}$ et al. In vitro synergistic effects of double combinations of beta-lactams and azithromycin against clinical isolates of Neisseria gonorrhoeae. $J$ Infect Chemother. 2006;12:172-176.

26 Sathia L, Ellis B, Phillip S et al. Pharyngeal gonorrhoea - is dual therapy the way forward? Int J STD AIDS. 2007;18:647-648.

27 Palmer HM, Young H, Winter A et al. Emergence and spread of azithromycin-resistant Neisseria gonorrhoeae in Scotland. J Antimicrob Chemother. 2008;62:490-494.

28 Chisholm SA, Neal TJ, Alawattegama AB et al. Emergence of high-level azithromycin resistance in Neisseria gonorrhoeae in England and Wales. J Antimicrob Chemother. 2009;64:353-358. 
29 Starnino S, Stefanelli P. Azithromycin-resistant Neisseria gonorrhoeae strains recently isolated in Italy. J Antimicrob Chemother. 2009;63:12001204.

30 Galarza PG, Alcala B, Salcedo C et al. Emergence of high level azithromycin-resistant Neisseria gonorrhoeae strain isolated in Argentina. Sex Transm Dis. 2009;36:787-788. 


\section{KEY MESSAGES}

Longitudinal surveillance of antimicrobial resistance in gonorrhoea showed ciprofloxacin is not suitable for treatment in Europe because of continued high levels of resistance.

The emergence of high-level azithromycin resistance is of great concern as widespread dissemination of these strains would eliminate azithromycin as a future treatment option.

Ceftriaxone is an appropriate treatment for gonorrhoea in Europe as all isolates tested were susceptible.

An upward ceftriaxone MIC drift was detected in the European gonococcal population, demonstrating that this situation needs to be monitored carefully.

Word Count: 2827

"The Corresponding Author has the right to grant on behalf of all authors and does grant on behalf of all authors, an exclusive licence (or non exclusive for government employees) on a worldwide basis to the BMJ Publishing Group Ltd to permit this article (if accepted) to be published in STI and any other BMJPGL products and sub-licences such use and exploit all subsidiary rights, as set out in our licence http://group.bmj.com/products/journals/instructionsfor-authors/licence-forms". 


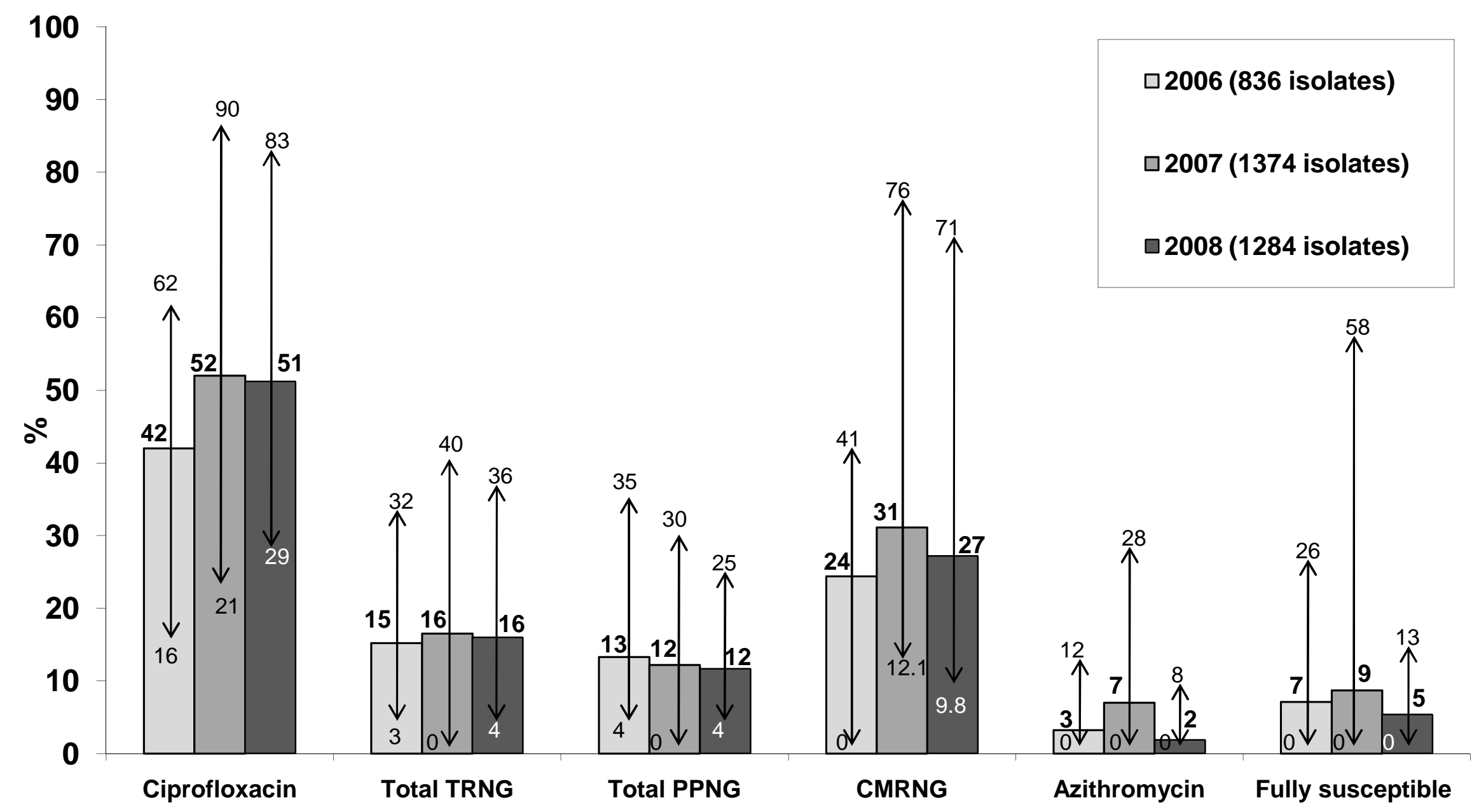

Figure 1. Overall incidence of resistant and fully susceptible N. gonorrhoeae (arrows indicate the lowest and highest percentage from participating countries (see Tables 2 and 3 ) 


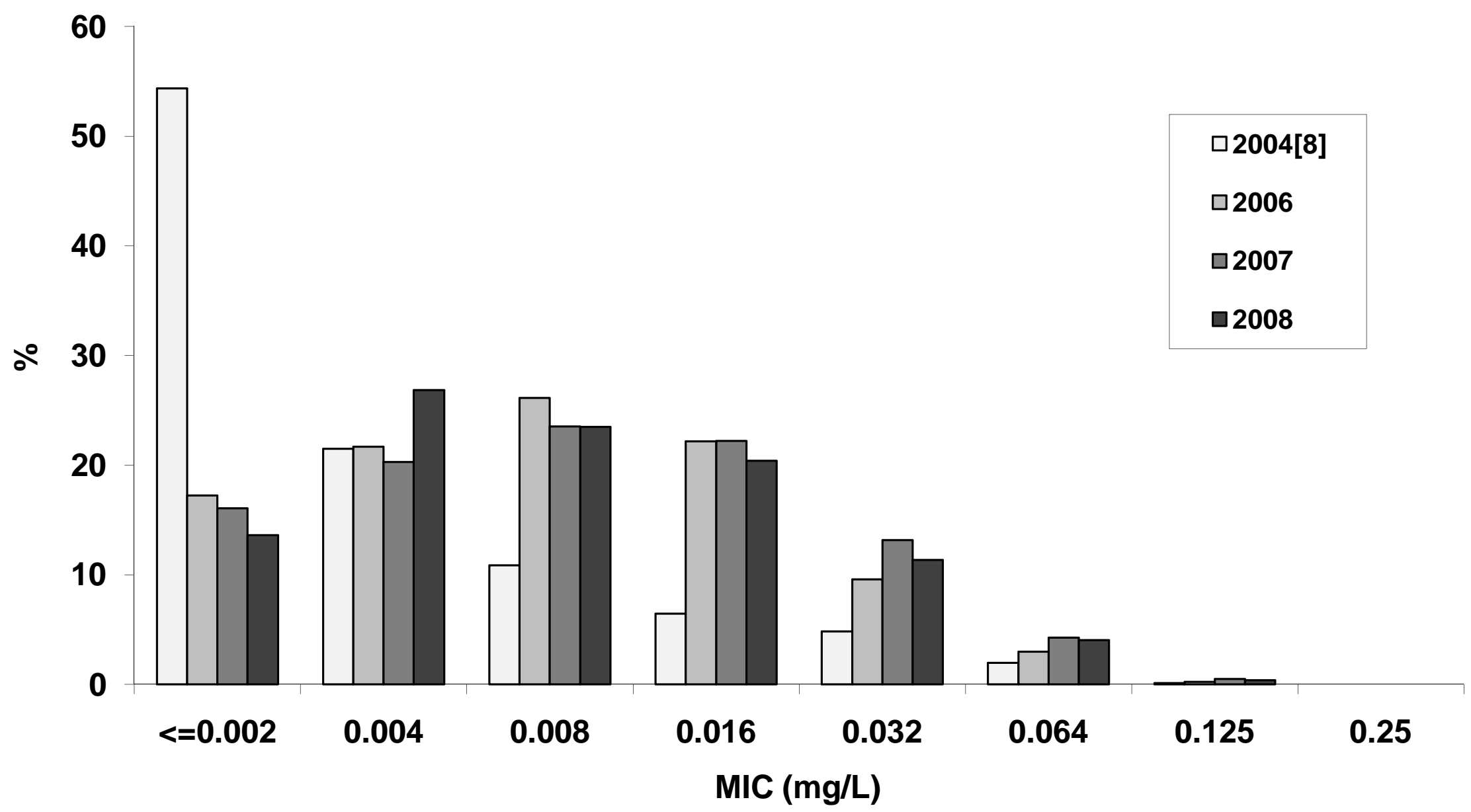

Figure 2. Ceftriaxone MIC distribution 